\section{CLINICAL LECTURES ON THE}

\section{EXAMINATION OF PATIENTS BEFORE OPERATING ON THEM.}

\section{Delivered at St. Bartholomew's Hospital.}

BY W. S. SAVORY, F.R.S.,

Surgeon to and Lecturer on Surgery at the Hospital; etc.

\section{II.}

THE last, though most important of all inquiries, is the personal ex amination of the patient - the study of his general condition and the scrutiny of his principal organs by the surgeon.

Now, independently of any particular disease in any organ, persons differ very widely indeed in their capability of bearing an operation, both in the power of sustaining shock and in the power of subsequent repair. Note that the capacity for reaction must not be confounded with the power of resistar $c$ ce. Indeed, as the rule, they are inversely proportionate to each other. A certain degree of shock may produce very obvious disturbance of the system in the young, which, nevertheless, soon subsides. In the old, the same injury may be attended with scarcely any visible effect; yet, when an impression is made, it endures. So the influence of shock is more manifest, but more transitory in the young ; less obvious, but more fatal in the old.

As life declines the vital powers diminish, and this loss becomes strikingly apparent when an injury or disease leads to an increased demand upon the resources of the system. There is less power in reserve, if it may be so expressed-less constitutional capital. In old age, the system may be equal to the task of maintenance, but it is far less capable of the extra exertion of repair. Those in advanced life are slow to rally. Reaction fails. But, independently of age, you continually hear it remarked that such or such a one is a good or bad subject for an operation, and this, not because of the presence or absence of any local or general disease commonly so-called, but because of his bodily condition, of his make or build, of his temperament or organisation. Thus an excess of fat, either locally or generally, is not a favourable circumstance. Adipose tissue is in the way of the healing of a wound, and very favourable to suppuration. Moreover, fat people usually bear the stress of constitutional disturbance worse than others. Disorders of the circulation tell more upon them, and they are especially unable to contend with any embarrassment of the respiration.

Persons, too, of what is termed gross habit of body, who are also usually too fat, but who give evidence of being out of condition by worse signs ; whose tissues throughout are too succulent ; whose minute vessels, on various parts of the surface, as the cheeks and elsewhere, are too distinctly mapped out; whose breath is strongly odorous, and sometimes foul ; whose tongue is habitually coated-persons with signs like these are uncanny subjects for surgical measures. Their constitution is not clean. The wheels of life are clogged. Their blood and tissues are overloaded with the products of retrograde metamorphosis in stages short of that in which they should be expelled. They stand very little in the way of fever, and are wont to go out suddenly. Beware of subjecting people in this state to the shock of an operation or to much local injury; and if it must be, look out for some evidence of blood-poisoning, such as erysipelas. And it is the more incumbent on us to pay attention to this untoward condition, because we may very often do much to correct it. Associated with this state, at least in many instances, and holding to it, in great measure, the relation of cause to effect, are unhealthy habits ; habits of excessive bodily indulgence; of excess of stimulants and of food too, and want of active exercise-in a word, habits which tend to overcharge the system and hinder the activity of healthy change. Now, of course, much of this may be amended, and often in a comparatively short time. The danger of suddenly interfering with confirmed habits in unstable constitutions is proverbial; and one would, if time allowed, try to bring about a better state of things more gradually, watching on the way. But even when we cannot have this advantage, it is preferable to bring about some change more suddenly than to have to deal with matters as they stand. At all events, remember that, as I have already said, we try the experiment under far more favourable conditions before an operation than after it; and remember that we can hardly carry a case through the effects of a considerable operation without subjecting our patient to a change of this kind. Far better, then, let me repeat, to see how he can bear the change without the addition of an operation than to call on him, without any previous preparation, to contend with both. Therefore, if you can possibly manage to delay the operation for a week or two you may, in most instances, turn the time at your command to very good account. Regulate his diet, encourage exercise if he can take it ; at all events, supply him freely with fresh air, and clear out the alimentary canal occasionally. If such patients do not improve somewhat under these measures, you learn to place their condition more to the account of their constitution and less to that of their habits; and if they show signs of giving way under such discipline, you have your eyes more fully opened to the prospect of an operation.

And this leads me to a further question-a question of great moment. I suppose if any one, who had not observed or reflected on the subject, were asked, which of two persons would be likely to bear a large operation better; one who submitted to it in the full tide of health and strength and active exercise, and the other after months of much suffering, close confinement to bed, and consequent exhaustion; he would reply, without hesitation, that there could be hardly a comparison, and wonder what was meant. So the difference is usually very marked, but, I venture to say, most frequently in favour of the invalid. Watch, I pray you, these matters for yourselves. It will not involve the scientific use of the imagination, but only observation of fact, and very moderate power of drawing conclusions therefrom. Compare cases, for example, of primary amputation for injury upon robust persons, with cases of amputation for long.standing disease upon persons apparently almost worn out by it. I think we have been somewhat misled in this matter by statistics. Tables of statistics of the results of primary and secondary amputation, if only studied in the form in which they are presented to us, point to the conclusion that primary amputations are more successful than secondary ones. I cannot stop now to criticise these calculations, and I hope to have another opportunity of pointing out a fallacy which I believe to underlie this great question. Let it pass now, with the remark only that I demur to any objection founded on such statistics to the view I am endeavouring to bring before you. And if the fact be as I have represented, can any explanation be offered of it? Yes; I think so. I have only just alluded to the fully recognised danger of any great and sudden change of habit in persons who have weak points about them. In old persons, for example, we are, or ought to be, especially alive to this. Why, in the treatment of fracture of the neck of the femur, does the surgeon avoid splints, if possible, and try to set the patient up as soon as he can bear to be moved? Because he knows very well that old persons soon succumb to the shock caused by sudden change in their mode of life-by the great change from their daily habits to confinement in an enforced position. Bed-sores are not the only troubles apt to wait on confinement, and with care these may be avoided or the blan of treatment modified upon the first hint of their approach; but ro care or foresight can escape the graver evil. Now, if such great and sudden interrup. tion of the habits of life be so potent for mischief in some, surely it must, in a considerable degree, press upon most; and when you add this to the shock of a large operation, you have weighted your robust patient against the feeble invalid, too heavily in proportion to whatever advantage he may have in constitutional power. Moreover, there is the further fact that, in the case of the invalid who suffers an operation for the removal of some chronic disease, his illness and weakness are maintained or aggravated by continual irritation or exhausting discharges. Now an operation, though severe in itself, gives him the great benefit of relief from this, and thus he rebounds, not unfrequently, with surprising elasticity.

You must not overlook the fact, however, that in some instances this condition of exhaustion may have been carried too far. Even if the patient have strength enough to rally from the operation itself, he may not have sufficient power left for the purpose of repair. If you watch such cases you will, from time to time, observe that, after the repair of a wound or injury, which has made great and long continued demands on a patient's strength, has been carried to a certain point, matters become very languid or stationary. From day to day or from week to week there is little, if any, advance. The granulations do not become actually unhealthy, but they grow paler, flabby, and, perhaps, with this the powers generally begin to flag. It seems as if, in the previous outlay, the patient had expended all his constitutional capital, that the power in reserve by which extraordinary demands are met and mischief repaired had been, for the present at least, used up. I need hardly stay to point out the indications in such a condition as this. You would not, if you could help it, subject any one under these circumstances to the risk of an operation. You would, of course, decline to make any farther demand on him, until, by change of air and other measures, his powers had been, in some degree, restored. In hospitals such a condition is too often seen, and as an illustration of it I may refer 
to a case which is at present under observation in Kenton Ward. This man, about thirty years of age, was admitted several weeks since with extensive injury to the right leg. The integuments were stripped off the whole of the front surface from just below the knee to the ankle, laying bare the tibia for several inches. His previous history was far from satisfactory. He had drunk excessively. The flap was replaced, but the greater portion of it soon sloughed, and the whole wound became foul and, indeed, phagedænic. Then he had a severe attack of delirium tremens, which for some days threatened to prove fatal. The leg and thigh began to swell, inflammation spread throughout the limb, and large dusky patches appeared in the neighbourhood of the wound and wandered upwards. The question of amputation was raised more than once, but on each occasion it was thought best, at least, to postpone it. Then the delirium passed away and he became calmer and began to sleep naturally, but the leg for awhile afterwards continued in a shocking state; large sloughs formed and came away, and the surface of the tibia was obviously dead. At length, however, the wound began to clean and the surrounding disturbance to subside, and so, in the course of another week or two, his pulse, tongue, and aspect became natural, and the wound covered everywhere with healthy granulation. Soon a thin layer of bone exfoliated from the surface of the tibia, and granulations covered also the living bone beneath. Then for some time longer the wound continued to contract and its edges to close in ; but the rate of progress gradually became slower, until it stopped altogether and matters came apparently to an absolute stand. still. But he made no complaint; he fed and slept well; his pulse was quiet ; his tongue clean ; his aspect good ; he even gained somewhat in flesh. Then portions of skin were grafted on the ulcers-very many over and over again ; and some of them are living and, perhaps, very slowly enlarging. But there is so much of repair yet to be carried out; the wound is still so large and gives so little evidence of any change for the better, although the entire surface appears quite healthy, and we are continually pointing to it in illustration of the characters of healthy granulation, that the only chance for the man is to give him change of air. In this case it would seem as if whatever power in reserve he had, had been temporarily, at least, exhausted; and that, unless it can be in some measure restored, he must lose his limb or his life, or perhaps even both.

[Since this was written, the man has been removed to another ward. After remaining for awhile in the same state, the wound began gradually again to amend, and now it is closed.]

Again, I have lately seen a case in which, in consequence of the failure of the wound to heal after removal of a portion of the foot, another amputation was performed at the ankle. But the second wound also, after showing some signs of favourable action, became stationary, and then suppuration extended up the leg between the tendons and muscles. Instances of this sort might be multiplied.

It is unfortunate when patients are reduced to such an extremity as this ; but it is the result, you see, of the heavy tax which has been for a long while levied upon the constitution by the local mischief and subsequent drain. And, indeed, such a result can excite no surprise. It is rather a matter of astonishment that persons who have gone through so much, can still recover so well as they usually do from a severe operation. And of this I know no better explanation than the one just offered-that, although confinement to bed or a couch is, in itself, in some respects, a source of weakness, the careful observance of good rules, the regulation of diet, and the exclusion of baneful habits is, on the other hand, a source of great gain. Then add to this that the great shock associated with certain operations is avoided, and that beyond all, in some cases, the patient has the advantage of sudden release from an exhausting disease to set in balance against the demands of an operation.

But, now, beyond these general advantages of rest and previous preparation, there are, in certain cases, others more local and definite. In some instances I think it is hardly too much to say that rest before an operation is almost as important as rest afterwards. The principle of this has been long ago and often insisted on, but the practice, I venture to say, is usually too much neglected. To take a striking illustration. Suppose you had to remove a loose cartilage from the knee-joint, do you think it would be wise to let your patient move about up to the time of the operation? You would be very properly shocked by any proposal to let the joint loose immediately afterwards. You would, of course, secure rest by a splint and insist upon absolute quietude. But would that be enough? Do you think that a joint which has been an active one up to the time when you wound it, to say nothing of the irritation to which it is subjected, is in the most favourable state to recover from the injury which you inflict? Cannot you see at once how much you would gain by placing the joint at absolute rest for some days previously to the operation? Nay, it is to be feared that the full advantage of this is not always foreseen. But reason suggests and experience confirms the fact that a joint thus, for some time previously, secured loses much of its irritability, of its disposition to resent the injury you must inflict ; that when its functions as a joint are in abeyance very gradually its behaviour as a joint is, in some measure, lost too. If there were fluid or other obvious signs of irritation in the joint, the need of previous rest would be so plainly indicated that he must be blind indeet who could not see it. But without this or any evidence of special disturbance, even arguing as if the joint were quite healthy and had nothing wrong in it, the great advantages of rest previous to the infliction of injury would be clearly seen by every well-educated surgeon.

Granted that this is a signal instance, yet the principle involved is of almost universal application. Perhaps it is not acknowledged so unreservedly, assuredly it is not carried out so fully as it ought to be. Some considerations, for the most part trivial, come in the way of it. It is often objected to as inconvenient, as causing delay. But if the surgeon get less credit for the foresight which averts danger than for the skill which meets it, he must know that his work in the former case is above his work in the latter, inasmuch as prevention is better than cure.

Under the head of temperament and organisation, I include character and disposition-the manner of man or woman your patient may be. That, apart from all influence of bodily constitution, people vary very widely in the way in which they bear injury, is a matter familiar to every one. You hear of persons of good courage, who are capital subjects for operation; and of others who have no pluck, as it is called, and so on, But such expressions of opinion are wont to come of very superficial observation. It is not accurate to affirm that courage is the best qualification, in this direction, for an operation, and fear the worst. The question is a larger one, and must be referred to the whole temperament of the individual. As a rule, women are unquestionably better subjects, in this respect, for injury or operation, than men ; not because they usually have more courage, in the ordinary acceptation of the term, but because they have, in this sense, more endurance. It is the passive rather than the active quality which avails them. If they can do less, they can suffer more. And, again, see the advantage of calmness and resignation as opposed to impatience and restlessness. A man will often meet the suggestion of an operation as a soldier will volunteer for a forlorn hope, while the hint of such a thing to a woman will sometimes prostrate her. But then each has to submit to it, and when the thing is done, as time goes on, qualities of another kind come into play, in which, in her turn, the woman surpasses the man. So, again, children have an enormous advantage over both men and women. They are terrified enough at first, and afterwards at times, but depression does not abide with them. With them memory is not obstinate, or hope absent. They live only in the present, and happily escape the despondency which, in older minds, is so apt to arise out of the past or future.

Gentlemen, believe me, such considerations as these, on which a volume might be written, are not unworthy of your consideration. Attention to such signs, and an honest endeavour to interpret and understand them, will not only avail you in your actual practice as surgeons, but will also, if rightly used, help you largely to secure the confidence of your patient. Remember that, in order to attain the highest degree of success possible to your art, you have in some measure to understand him or her, as well as the nature of and treatment required for the disease about which you are consulted. And you have not months or even weeks of personal acquaintance in which to learn this lesson; but then you may observe character and temperament under circumstances powerful beyond all others to show them, and you may, if you wfll, turn what you learn to good purposes for your patient.

AN USEFUL HINT. - The following advertisement appears in one of our American medical contemporaries.

"Physiological and Pathological Laboratory. - The undersigned are prepared to undertake chemical and microscopical investigations for those who have not at their disposal the time or appliances necessary for the purpose. The urine and its sediments, calculi, blood, milk, morbid growths, and other products of normal and pathological processes, will be examined microscopically, and by chemical analysis, qualitative or quantitative, as may be desired. The charges will be proportioned to the amount of labour required in each case. Communications and material for examination should be sent," etc.

The idea is, we think, a good one. Many practitioners who have not the skill, practice, or appliances for such investigation, are content to pass over dubious questions, or to leave undetermined and unwatched varying clinical conditions, from the want of an accessible authority to whom they could apply with confidence and without encroaching upon friendly good-will. Some of our younger experts might perhaps with advantage take the hint. 